This item was submitted to Loughborough's Research Repository by the author.

Items in Figshare are protected by copyright, with all rights reserved, unless otherwise indicated.

\title{
Body proportionality and adiposity are not related in 6- to 8-year-old Yucatec Maya children
}

PLEASE CITE THE PUBLISHED VERSION

https://doi.org/10.1002/ajhb.23254

PUBLISHER

(c) Wiley

VERSION

AM (Accepted Manuscript)

\section{PUBLISHER STATEMENT}

This is the peer reviewed version of the following article: VAZQUEZ-GOMEZ, A. ... et al, 2019. Body proportionality and adiposity are not related in 6- to 8-year-old Yucatec Maya children. American Journal of Human Biology, 31 (4), e23254, which has been published in final form at https://doi.org/10.1002/ajhb.23254. This article may be used for non-commercial purposes in accordance with Wiley Terms and Conditions for Use of Self-Archived Versions.

\section{LICENCE}

CC BY-NC-ND 4.0

\section{REPOSITORY RECORD}

Vazquez-Gomez, Alonso, María Luisa Ávila-Escalante, Hugo Azcorra, Maria Ines Varela-Silva, and Federico Dickinson. 2019. "Body Proportionality and Adiposity Are Not Related in 6- to 8-year-old Yucatec Maya Children”. Loughborough University. https://hdl.handle.net/2134/37751. 


\section{American Journal of Human Biology}

WILEY

\section{Body proportionality and adiposity are not related in 6 to 8- year-old Yucatec Maya children}

\begin{tabular}{|r|l|}
\hline Journal: & American Journal of Human Biology \\
\hline Manuscript ID & AJHB-18-0189.R2 \\
\hline Wiley - Manuscript type: & Short Report \\
\hline Autho Submitted by the & n/a \\
\hline Complete List of Authors: & $\begin{array}{l}\text { Vazquez-Gomez, Alonso; Centro de Investigacion y de Estudios } \\
\text { Avanzados Unidad Merida, Ecología Humana; Instituto Mexicano del } \\
\text { Seguro Social, Nutrición } \\
\text { Avila-Escalante, María Luisa; Universidad Autonoma de Yucatan, } \\
\text { Licenciatura en Nutrición } \\
\text { Azcorra, Hugo; Centro de Investigación y de Estudios Avanzados del } \\
\text { Instituto Politecnico Nacional, Departamento de Ecología Humana } \\
\text { Varela-Silva, Maria; Loughborough University, Human Sciences } \\
\text { DICKINSON, FEDERICO; Centro de Investigación y de Estudios } \\
\text { Avanzados, Departamento de Ecología Humana }\end{array}$ \\
\hline Keywords: & body proportionality, adiposity, stunting, obesity, Maya children \\
\hline
\end{tabular}




\title{
Body proportionality and adiposity are not related in 6 to 8-year-old Yucatec
}

\section{Maya children.}

Short title for header: Body proportions and adiposity in Maya children.

\author{
Vazquez-Gomez, Alonso ${ }^{1 \dagger}$ \\ Ávila-Escalante, María Luisa ${ }^{2}$ \\ Azcorra, Hugo ${ }^{1}$ \\ Varela-Silva, Maria Inês ${ }^{3}$ \\ Dickinson, Federico ${ }^{1}$
}

${ }^{1}$ Departamento de Ecología Humana, Centro de Investigación y de Estudios Avanzados del Instituto Politécnico Nacional (Cinvestav), Unidad Mérida, Mérida, Yucatán, México.

${ }^{2}$ Facultad de Medicina, Universidad Autónoma de Yucatán, Mérida, Yucatán, México.

${ }^{3}$ Lifestyle for Health and Wellbeing Research Theme, School of Sports, Exercise and Health Sciences, Loughborough University, Loughborough, United Kingdom.

Number of text pages: 6; Number of tables: 2

Address for correspondence:

Vazquez-Gomez, Alonso

Telephone: +529991513005

Email: carlos.vazquez@cinvestav.mx

Financing information:

Contract grant sponsor: Consejo Nacional de Ciencia y Tecnología (Conacyt); Contract grant numbers: 168047 (for the research project) and 308942 (for fellowship to AV-G). 


\begin{abstract}
Objective: To analyze the association between relative leg length - RLL - (leg length x 100/height) and adiposity in a sample of 6 to 8-year-old children of Maya ancestry from Motul and Merida, Mexico.

Methods: This cross-sectional study included 260 children (128 girls) measured between 2011 and 2015. The RLL was used as a measure of body proportionality. Linear regression models were performed to examine the association between RLL (predictor) and three adiposity indicators (outcome variables): fat mass index $\left(\mathrm{kg} / \mathrm{m}^{2}\right)$, waist circumference (z-score) and sum of triceps and subscapular skinfolds (z-score).

Results: The prevalence of stunting was 12\%, and a higher prevalence (19\%) of short RLL (leg stunting) was found. The prevalence of overweight and obesity were 16 and $20 \%$, respectively, but the highest was found for abdominal obesity (40\%). None of the adiposity indicators were related to RLL ( $p>0.05)$, even after adjusting for the influence of children's sex and age.

Conclusions: Our results suggest that the coexistence of short RLL and high body adiposity is not observed in all populations. Our findings do not discount the possibility that a negative association between RLL and adiposity is expressed at older ages.
\end{abstract}

Key words: body proportionality, adiposity, stunting, obesity, Maya children. 


\section{Introduction}

The objective of this study was to analyze the relationship between RLL and total, abdominal, and peripheral adiposity in a sample of 6 to 8 -year-old children of Maya ancestry in the cities of Motul and Merida, Yucatan, Mexico. Having short legs for total height (short RLL) is one of the results of chronic poor nutritional conditions (Leitch, 1951). Suffering undernourishment in early life stages can induce metabolic adjustments that may lead to unhealthy outcomes in body composition, and this, in turn, increases the risk of future metabolic diseases (Wells, 2016). Some studies, conducted in different countries, such as United States (Frisancho, 2007), United Kingdom (Pliakas and McCarthy, 2010) and China (Zhang, Chu and Zhao, 2016) have reported that children with generally lower RLL tend to accumulate more total adiposity or at different regions of the body compared to children with higher RLL. However, the last two of these studies used BMI to characterize body adiposity and the risk of overweight. Accordingly, in this study, we test the hypotheses that children's RLL will be negatively related to 1: fat mass index (FMI), 2: waist circumference (WC), and 3: sum of triceps and subscapular skinfolds (SumTS+SS). These hypotheses have not been tested in Maya children; most of the Maya people from Yucatan live in conditions of poverty (Bracamonte y Sosa and Lizama Quijano, 2003), which contribute to explains the coexistence of stunting and overweight at both population and household levels (Varela-Silva et al. 2012), with a higher likelihood for leg stunting as well.

\section{Methods}

Population study

A cross-sectional study was implemented between September 2011 and April 2015 involving 260 children (128 girls) of Maya ancestry living in the cities of Motul and Merida, in the state of Yucatan, Mexico. Three inclusion criteria used for children were that: 1) their mother had both maternal and paternal Maya surnames (Maya surnames were used as a proxy for Maya genetic ancestry); 2) their age must be between 6.00 to 8.99 years, and 3) they had to attend public schools. In Yucatan, elementary 
school is compulsory, therefore $97 \%$ of children attend school (INEGI, 2015). Participant recruitment procedures and selection criteria about the study population are described in detail in Azcorra Pérez (2014).

\section{Ethical considerations}

The research project was reviewed and approved by the Bioethics Committee for the Study of Human Beings at Cinvestav (Centro de Investigación y de Estudios Avanzados del Instituto Politécnico Nacional) and the Loughborough University Ethics Advisory Group (R11-P133). Mothers provided informed consent for their child's participation in the study, and the children provided their verbal assent.

\section{Physical measurements}

Height $(\mathrm{cm})$, weight $(\mathrm{kg})$, sitting height $(\mathrm{cm})$ and triceps and subscapular skinfolds $(\mathrm{mm})$ were measured following standardized protocols (Lohman, Roche and Martorell, 1988), using a Seca 881 scale for weight, Martin type anthropometers for height and sitting height and Harpenden HSB-BI calipers for skinfolds. Leg length (LL) and RLL were calculated using equations 1 and 2.

$$
\begin{aligned}
& \mathrm{LL}_{\mathrm{cm}}=\text { height }_{\mathrm{cm}}-\text { sitting height }_{\mathrm{cm}} \\
& \text { RLL }_{\%}=\left(\mathrm{LL}_{\mathrm{cm}} \times 100\right) / \text { height }_{\mathrm{cm}}
\end{aligned}
$$

Waist circumference was measured with a tape placed horizontally on the median line between the last floating rib and the highest portion of the iliac crest. Waist-to-height ratio $\left(\mathrm{WHR}=\mathrm{WC}_{\mathrm{cm}} /\right.$ height $\left._{\mathrm{cm}}\right)$ was used as an indicator of abdominal level fat, and SumTS+SS was used as an indicator of peripheral fat. All measurements were taken in schools by standardized personnel, generally two hours after breakfast and before the recess and school physical education activities. A research assistant of the 


\begin{abstract}
Laboratory of Somatology at Cinvestav-Mérida, with more than 20 years of experience in anthropometry regularly trained five measurers for the duration of the project, then there were three standardization sessions in which only $<5 \%$ of inter-observer technical error of measurement was acceptable.
\end{abstract}

For descriptive purposes, z-score values were calculated for height, LL, RLL, body mass index (BMI), WC and SumTS+SS based on Frisancho's Comprehensive Reference (2008). This reference was selected because it included Mexican-American children and because there are no anthropometry references available for Mexicans. To be under the 5th percentile was used to classify a child as: a) stunted, according to height-for-age, b) leg length stunted, according to leg length-for-age and c) with short RLL, according to RLL-for-age.

Children were classified as at risk of overweight when their BMI-for-age was $\geq 85$ th percentile, and at risk of obesity when it was $\geq 95$ th percentile. Fat-free mass (equation 3 ) was calculated by bioimpedance body composition analysis (Bodystat 1500 MDD) and the equation developed by Ramírez et al. (2012) which is the most reliable one for 6 to 12-years old Maya children since the sample from which the equation was developed included participants from this ethnic group. Fat mass (equation 4) and the FMI (equation 5) were then calculated. The latter value was used as an indicator of total adiposity, instead of body fat percentage or fat mass, because it is adjusted for height and the measurement unit is similar to that of the BMI $\left(\mathrm{kg} / \mathrm{m}^{2}\right)$.

$$
\begin{aligned}
& \text { Fat-free mass } \left.{ }_{\mathrm{kg}}=0.661 \times\left(\text { height }_{\mathrm{cm}}\right]^{2} / \text { resistance }_{\Omega}\right)+0.200 \text { x weight }_{\mathrm{kg}}-0.320 \text { (3) } \\
& \text { Fat mass }_{\mathrm{kg}}=\text { weight }_{\mathrm{kg}}-\text { fat-free mass }_{\mathrm{kg}} \\
& \mathrm{FMI}_{\mathrm{kg} / \mathrm{m}^{2}}=\text { fat }_{\text {mass }} \mathrm{kg} /\left[\text { height }_{\mathrm{m}}\right]^{2}
\end{aligned}
$$

Statistical analyses 
Fisher's exact test was used to examine the differences in the proportions of stunted/leg length stunted children and stunted/short RLL children. To test the hypotheses, we performed three linear regression models to examine the relationship between RLL and adiposity indicators. We used RLL as the predictor variable and three adiposity indicators as the outcome variables; FMI $\left(\mathrm{kg} / \mathrm{m}^{2}\right)$; WC (z-score) and SumTS+SS (z-score). The three models were adjusted for children's sex. Only the model for FMI was additionally adjusted for age (years). All models satisfied the normality of the residuals.

Significance level was set at $\alpha<0.05$.

\section{Results}

Stunting was present in $12 \%(n=31)$ of children, but the proportion of children with stunted leg length $(28 \%, \mathrm{n}=73)$ was significantly higher $(\mathrm{p}<0.01)$. Near to one fifth $(19 \%, \mathrm{n}=48)$ of children had short RLL, a proportion that significantly differ from that of stunting $(\mathrm{p}<0.01)$.

[Table 1]

Children in this sample showed higher adiposity levels than the reference population. Sixteen percent $(n=42)$ and $20 \%(n=53)$ of children met the criteria for overweight and obesity, respectively. Forty percentage $(n=105)$ of children had a WHR $>0.50$, indicating risk for abdominal obesity.

The three regression models, however, showed no significant relationship between RLL and the three adiposity indicators $(\mathrm{p}>0.05)$, even after adjusting for sex and age (Table 2$)$.

[Table 2] 


\section{Discussion}

Our results do not support the hypotheses that lower RLL is associated with higher values of body adiposity. Some evidence indicates that lower RLL children tend to have more BMI (Pliakas and McCarthy, 2010; Zhang et al. 2016), however, BMI has serious limitations as a proxy for fat (Bogin and Varela Silva, 2012) because it is just an indicator of weight-for-height and individuals with the same weight could have different amounts of fat mass or fat free mass, as well, the variation in body proportionality results in different values in the prevalence of overweigh using BMI classification as Norgan (1995), clearly demonstrated in his study of Australian aborigines. Therefore, our analysis shows more accurate results about the relationship between body proportionality and adiposity. Although not statistically significant, it might be relevant that slope coefficients in all three models (see Table 2) are positive, not negative as expected from other studies (Frisancho, 2007; Pliakas and McCarthy, 2010; Zhang et al. 2016). Our results suggest that a negative association between RLL and body adiposity is not observed in all populations. We do not have a clear explanation for these discrepancies in results. However, it is possible that our results are explained by the fact that overnutrition tend to accelerate growth (Vignolo, Naselli, Di Battista, Mostert and Aicardi, 1988). In fact, overweight/obese children tend to be taller than their normal weight counterparts or above average (Papadimitriou, Gousi, Giannouli and Nicolaidou, 2006). If excessive gain fat tends to promote linear growth, as has been proposed, increments in lower body segments could be expected. In our sample, overweight/obesity is a widespread condition; thirty-six and forty percent of children met the criteria for excessive BMI and WHR, respectively.

In their study with 2-20 years old Mexican-American children and young adults, Frisancho (2007) found that individuals with low RLL (z-score $<-1.036$ ) had more subcutaneous fat compared to those who showed high RLL (z-score $>+1.036$ ). In contrast, we did not find in our sample a significantly relation between RLL and SumTS+SS. However, Maya children are notably different, in terms of socioeconomic and biological conditions, from studied populations in above cited reports that comes 
from developed world; our sample seems to be poorer, that implies limited access to safe water, health services, an insanitary excreta disposal and balanced diet. Additionally, nutritional dual-burden present in Maya households (Varela-Silva et al. 2012) could be promoting excessive adiposity early in life. It is a particular scenario, considering many ecological factors, from a human ecology perspective.

It is also possible that the studied children were still too young to manifest the influence of differentiated growth trajectories and these would become significant after the pubertal growth spurt. The present results do not discount the possibility that the studied children will exhibit linear growth trajectories and body composition during adolescence and adulthood that influence the phenotype observed in the adult Maya population. Future research needs to include the use of biochemical markers for blood glucose, cholesterol and triglycerides, or clinical markers such as acanthosis nigricans, to estimate individuals' metabolic risk at early ages and to support adiposity indicator results.

\section{Acknowledgements}

The authors thank the participating children and their mothers for their time and trust. Graciela Valentín was in charge of field logistics and participated in data collection. Paulina Cauich, Frida Legorreta and Adriana Vázquez also collected data. Thanks are also due the Yucatan State Ministry of Education (Secretaría de Educación del Gobierno de Yucatán) for permission to enter the schools. The research reported here was partially funded by the Conacyt-Ciencia Básica (168047), and AV-G received a graduate scholarship from Conacyt-Becas Nacionales (308942). The authors declare no conflict of interest.

Author contributions:

AV-G and FD designed the study; AV-G analyzed the data; AV-G and FD wrote the manuscript draft; FD, HA and MVS designed the project of which this study forms a part; and MLAE, HA and MVS revised and commented on the manuscript. 


\section{Literature cited}

Azcorra Pérez, H. S. (2014). Intergenerational factors that shape the nutritional status of urban Maya households in Merida, Mexico. A 3-generations study [PhD Theses]. Leicestershire: Loughborough University. 280 p., available at https://dspace.lboro.ac.uk/2134/14159.

Bogin, B., Varela-Silva, M. I. (2012). The body mass index: the good, the bad, and the horrid. Bulletin der Schweizerischen Gesellschaft für Anthropologie 18, 5-11.

Bracamonte y Sosa, P., Lizama Quijano, J. (2003). Marginalidad indígena: una perspectiva histórica de Yucatán. Desacatos 13, 83-98.

Frisancho, A. R. (2007). Relative leg length as a biological marker to trace the developmental history of individuals and populations: Growth delay and increased body fat. American Journal of Human Biology 19, 703-710.

Frisancho, A. R. (2008). Anthropometric standards: An interactive nutritional reference of body size and body composition for children and adults. Ann Arbor: The University of Michigan Press.

INEGI. (2015). Panorama sociodemográfico de México 2015. Encuesta Intercensal (2015). México: Instituto Nacional de Estadística y Geografía. Available from: www.inegi.org.mx/programas/intercensal/2015/.

Leitch, I. (1951). Growth and health. British Journal of Nutrition 5, 142-151.

Lohman, T. G., Roche, A. F., Martorell, R. (1988). Anthropometric standardization reference manual. Champaign, IL: Human Kinetics Books.

Norgan, N. G. (1995). Body mass index and nutritional status: the effect of adjusting body mass index for the relative sitting height on estimates of the prevalence of chronic energy deficiency, overweight and obesity. Asia Pacific Journal of Clinical Nutrition 4, 137-139.

Papadimitriou, A, Gousi, T., Giannouli, O., Nicolaidou, P. (2006). The growth of children in relation to the timing of obesity development. Obesity 14, 2173-2176.

Pliakas, T., McCarthy, H. D. (2010). Association of leg length with overweight and obesity in children aged 5-15 years: A cross-sectional study. Annals of Human Biology 37, 10-22.

Ramírez, E., Valencia, M. E., Bourges, H., Espinosa, T., Moya-Camarena, S. Y., Salazar, G., AlemánMateo, H. (2012). Body composition prediction equations based on deuterium oxide dilution method in Mexican children: a national study. European Journal of Clinical Nutrition, 66,10991103.

Varela-Silva, M. I., Dickinson, F., Wilson, H., Azcorra, H., Griffiths, P. L., Bogin, B. (2012). The nutritional dual-burden in developing countries--how is it assessed and what are the health implications? Collegium Antropologicum 36, 39-45. 
Vignolo, M., Naselli, A., Di Battista, E., Mostert, M., Aicardi, G. (1988). Growth and development in simple obesity. European Journal of Pediatrics 147, 242-244.

Wells, J. C. K. (2016). The metabolic ghetto. An evolutionary perspective on nutrition, power relations and chronic disease. Cambridge, UK: Cambridge University Press.

Zhang, Y., Chu, Z., Zhao, J. (2016). Distribution of sitting height ratio and its association with body mass index among children and adolescents in Shandong, China. Biology and Medicine (Aligarh) 8(1):1000267.

\footnotetext{
† Current affiliation at Departamento de Nutrición, Hospital General Regional \#1 “Lic. Ignacio García Téllez”, Instituto Mexicano del Seguro Social (IMSS), Mérida, Yucatán, México.
} 
Table 1

Table 1. Mean (SD) values of anthropometric and adiposity variables by sex and age (years) groups.

\begin{tabular}{|c|c|c|c|c|c|c|c|c|}
\hline \multirow[b]{2}{*}{ Variable } & \multicolumn{4}{|c|}{ Male } & \multicolumn{4}{|c|}{ Female } \\
\hline & 6 & 7 & 8 & Z-scoret & 6 & 7 & 8 & Z-score ${ }^{\dagger}$ \\
\hline $\mathrm{n}$ & 36 & 49 & 47 & 132 & 38 & 44 & 46 & 128 \\
\hline Height $_{\mathrm{cm}}$ & $115.1(5.3)$ & 119.8 & $126.4(5.8)$ & $-0.65(0.88)$ & $114.4(4.2)$ & $119.7(6.1)$ & 125.4 & $-0.53(0.88)$ \\
\hline Weight $_{\mathrm{kg}}$ & $22.6(4.3)$ & $26.2(6.2)$ & $30.7(7.6)$ & $-0.15(0.92)$ & $22.7(4.4)$ & $25.8(5.6)$ & 29.1 & $0.15(0.93)$ \\
\hline $\mathrm{LL}_{\mathrm{cm}}$ & $52.4(3.3)$ & $55.2 \quad(2.8)$ & $59.2(4.0)$ & $-1.41(0.88)$ & $52.6(2.9)$ & $55.7(3.5)$ & $59.0 \quad(3.7)$ & $-0.80(0.88)$ \\
\hline RLL $_{\%}$ & $45.5(1.3)$ & $46.0 \quad(1.8)$ & $46.8(1.4)$ & $-0.96(0.82)$ & 45.9 (1.6) & $46.5(1.1)$ & $47.0 \quad(1.1)$ & $-0.90(0.76)$ \\
\hline $\mathrm{BMI}_{\mathrm{kg} / \mathrm{m}^{2}}$ & $16.9(2.3)$ & $18.1 \quad(3.3)$ & $19.0(3.5)$ & $0.91(1.03)$ & $17.3(2.6)$ & $17.8(2.5)$ & 18.2 & $0.71(0.99)$ \\
\hline $\mathrm{FM}_{\mathrm{kg}}$ & $6.6(2.5)$ & $8.1 \quad(3.6)$ & $10.0(4.2)$ & $\mathrm{N} / \mathrm{A}$ & $7.3(2.6)$ & $8.7(3.0)$ & $10.2 \quad(5.2)$ & $\mathrm{N} / \mathrm{A}$ \\
\hline $\mathrm{FMI}_{\mathrm{kg} / \mathrm{m}^{2}}$ & $4.9(1.7)$ & $5.5(2.2)$ & $6.1(2.2)$ & $\mathrm{N} / \mathrm{A}$ & $5.5(1.8)$ & $6.0(1.7)$ & $6.4(2.7)$ & N/A \\
\hline $\mathrm{WC}_{\mathrm{cm}}$ & $57.1(6.3)$ & $60.7 \quad(8.4)$ & $64.2(8.8)$ & $0.57(0.81)$ & $57.5(6.5)$ & $60.2(7.2)$ & $61.7(10.2)$ & $0.75(0.77)$ \\
\hline WHR & $0.5(0.1)$ & $0.5 \quad(0.1)$ & $0.5(0.1)$ & $\mathrm{N} / \mathrm{A}$ & $0.5(0.1)$ & $0.5(0.1)$ & $0.5 \quad(0.1)$ & $\mathrm{N} / \mathrm{A}$ \\
\hline SumTS $+\mathrm{SS}_{\mathrm{mm}}$ & $17.7(8.2)$ & $20.5(10.6)$ & $22.9(9.7)$ & $0.34(0.84)$ & $21.2(9.7)$ & $23.9(8.0)$ & $24.7(11.7)$ & $0.66(0.80)$ \\
\hline
\end{tabular}

†Z-score of all age groups, based on Frisancho’s Comprehensive Reference (2008); LL: leg length; RLL: relative leg length; BMI: body mass index; FM: fat mass; FMI: fat mass index; WC: waist circumference; WHR: waist-to-height ratio; SumTS+SS: sum of triceps and subscapular skinfolds. 


\section{Table 2}

Table 2. Regression models relating relative leg length to children's fat mass index, waist circumference and sum of triceps and subscapular skinfolds.

\begin{tabular}{lcccc}
\hline & $\mathrm{B}(\mathrm{SE})$ & $95 \%$ CI & p-value \\
\hline Fat mass index (FMI) ${ }_{\mathrm{kg} / \mathrm{m}}{ }^{2}$ & $0.135(0.110)$ & -0.08 & 0.35 & 0.221 \\
Waist circumference $_{\mathrm{z} \text {-score }}$ & $0.070(0.038)$ & -0.01 & 0.14 & 0.068 \\
Sum of skinfold $_{\text {z-score }}$ & $0.093(0.048)$ & 0.00 & 0.18 & 0.055 \\
\hline Model for FMI was adjusted for children's sex and age (years); models for waist \\
circumference and sum of skinfolds were adjusted for children's sex; SE: Standard \\
error.
\end{tabular}

